\title{
LA EXPRESIÓN DE LA INTIMIDAD EN EL SUJETO DESCENTRADO: EL DIARIO DE MARGA GIL ROËSSET ${ }^{1}$
}

\author{
THE EXPRESSION OF INTIMACY \\ IN THE DECENTERED SELF: \\ MARGA GIL ROËSSET'S DIARY

\section{M. ${ }^{a}$ Ángeles HERMOSILLA ÁLVAREZ \\ Universidad de Córdoba \\ fe1healm@uco.es}

\begin{abstract}
Resumen: Aunque el número de mujeres que han publicado textos autobiográficos ha sido escaso, en gran medida porque han preferido llevar a la autoficción los aspectos de su intimidad, algunas se decidieron a comunicar sus sentimientos y vivencias en determinadas circunstancias. Es el caso de Marga Gil Roësset, la artista que se suicidó por el amor no correspondido a Juan Ramón Jiménez. Indagar en las características de un yo femenino que toma la pluma para expresar su pasión amorosa en un diario y en las peculiaridades de su escritura es el objetivo de este trabajo.
\end{abstract}

Palabras clave: Sujeto descentrado. Escritura diarística. Intimidad. Marga Gil Roësset.

\begin{abstract}
Although the number of autobiographical texts written by women is scarce, due to a great extent to their preference to express their private aspects through self-fiction, some of them decided, under certain

\footnotetext{
${ }^{1}$ Este artículo se inscribe en el marco del proyecto de investigación franco-español "Figures et frontières de l'intime à l'époque contemporaine / Figuras y fronteras de la intimidad en la época contemporánea" (OPE-2017-0042), Universidad de Pau et des Pays de l'Adour EFM (FR 4153), ALTER (EA7504), ITEM (EA 3002), en colaboración con el grupo de investigación "Lenguajes" (HUM 224) de la Universidad de Córdoba (España) y el laboratorio "Arts Plastiques" (EA 7472) de la Universidad de Rennes 2 (Francia).
} 
circumstances, to communicate their own experience and feelings. This is the case of Marga Gil Roësset, the artist who committed suicide as a response to her unrequited love for Juan Ramon Jimenez. The aim of this paper is to make insights into the main features of a feminine self that takes up the pen to express her affectionate passion in her diary, as well as to focus on the particular traits of her writing.

Key Words: De-centered Self. Diary Writing. Intimacy. Marga Gil Roësset.

\section{SUJETO Y AUTORÍA FEMENINA}

Hablar de la mujer como sujeto, y más aún a principios del siglo pasado, en la época de nuestra autora, es problemático, porque, como puso de manifiesto en 1949 Simone de Beauvoir (1990a: 50), "la mujer se diferencia respecto al hombre, y no a la inversa; ella es lo inesencial frente a lo esencial. Él es el Sujeto, es el Absoluto; ella es la Alteridad". Es decir, ella, encerrada en lo biológico y lo doméstico, queda relegada a la inmanencia, mientras que el varón realiza acciones según unos objetivos, se realiza como persona y se proyecta en la trascendencia (Beauvoir, 1990a: 127-128), de modo que, de acuerdo con Violi (1991: 153-154) "ser mujer es constantemente antagónico y contradictorio con su estatuto de persona, de sujeto". Identificada con la naturaleza, ella ha pretendido acceder a la cultura y se ha encontrado con una tradición que la excluía, por lo que se ha visto obligada a realizar un desplazamiento del plano emotivo-sexual al intelectivo, una escisión que, aunque también puede presentarse en el hombre, no le afecta del mismo modo, ya que este enseguida se identifica como sujeto, ya inscrito en el discurso, mientras que para la mujer es una condición que solo puede alcanzar negando su particularidad sexuada.

Es por eso por lo que, cuando Sandra M. Gilbert y Susan Gubar (1998: 62-63) se preguntan dónde encajan las escritoras en la historia literaria descrita por Bloom, no encuentran respuesta, porque en ese modelo patriarcal los precursores son casi siempre masculinos y han reducido a estereotipos la imagen femenina. Por tanto - concluyen las estudiosas americanas - "la 'ansiedad hacia la influencia' que un poeta experimenta es sentida por una poeta como una 'ansiedad hacia la autoría", desde el momento en que la primera tarea de la escritora será 
contrarrestar las consecuencias de una socialización, cuyos términos ha de volver a definir, porque no podemos negar la existencia de un discurso social que, según ha analizado Marc Angenot (1989: 13 y ss.), rige todo lo que se narra y argumenta, todas las reglas de nuestras representaciones que en una sociedad organizan lo decible y aseguran, bajo la aparente diversidad, un discurso hegemónico basado en un sistema binario en el que lo femenino se asocia a la naturaleza, el cuerpo, los afectos, la subjetividad y lo privado, mientras que lo masculino, donde se asienta la cultura, se identifica con lo abstracto, la razón, la objetividad y lo público, una organización dicotómica que denunció Hélène Cixous (1995: 13-14). Y es que, a juicio de Giulia Colaizzi (1990: 16-17), el estructuralismo de LéviStrauss, con la división del trabajo como base de su teoría del parentesco, y el psicoanálisis lacaniano, que ha sexualizado el sujeto con atributos masculinos y ha considerado a la mujer como el negativo de la imagen especular del hombre, constituyen dos patrones que entran en pugna con las nociones de subjetividad y significación en lo concerniente a la posición de las mujeres.

Así pues, el problema del sujeto es fundamental, en opinión de Judith Butler (2001: 34), para la política, y, especialmente, para la política feminista, en la medida en que, según el esclarecedor trabajo de Antonio Campillo Meseguer (2001), hasta finales del siglo XVIII, las diferentes formas de dominación habían intentado naturalizar los diversos tipos de identidad, pero los movimientos de liberación de los dos últimos siglos han historizado las identidades transmitidas para mostrar su carácter instituido y ensayar nuevas formas de identidad.

Autores como Mary Wollstonecraft, Karl Marx, Franz Boas y Friedrich Nietzsche estimularon la reelaboración de la identidad personal de las mujeres, los obreros, los indígenas y los incrédulos respectivamente (Campillo Meseguer, 2001: 224) y sus ideas empezaron a cuestionar la concepción cartesiana del sujeto hombre como un yo unitario, coherente y racional para dar paso a otra en la que el individuo aparece configurado por las fuerzas históricas y sociales, a las que, con la teoría psicoanalítica, se suman las del inconsciente.

En esta reformulación han sido las teorías filosóficas postmodernas las que más lejos han llevado a cabo la politización y la historización de la identidad personal, que ya habían iniciado las filosofías de impronta fenomenológica y hermenéutica. Como estas, consideran que el sujeto es una 
creación lingüística, inseparable de las relaciones sociales entre individuos, pero el pensamiento postestructuralista señala la interdependencia de las relaciones de comunicación y de dominación (Campillo Meseguer, 2001: 225-226). De este modo Michel Foucault (1979: 170-171), en Microfísica del poder, afirma que las relaciones de poder están implicadas en otros tipos de relación (sexuales, familiares, de alianza) y su entrecruzamiento genera hechos de dominación cuyos procedimientos son reajustados por estrategias globales, una realidad que coincide con numerosas formas de resistencia. Por ello no resulta adecuado partir de un hecho masivo de dominación, sino más bien considerar la producción multiforme de relaciones de poder que son parcialmente integradas en estrategias de conjunto. Desde estos postulados se comprende la tarea que Colaizzi (1990: 25) reserva al feminismo: "no un discurso unitario contra la teoría o el poder, sino una articulación de múltiples discursos acerca del poder", una aseveración que evite las dicotomías y, en palabras de Judith Butler (2001: 47), "la unidad de la categoría de las mujeres, que ha negado la multiplicidad de intersecciones culturales, sociales y políticas en que se construye el conjunto concreto de "mujeres"'.

Nos encontramos, pues, ante una concepción descentrada y fragmentada del sujeto, que, lejos de ser monolítica, no descansa, además, en una teoría previa ni es una sustancia, sino una forma cambiante, ya que un mismo sujeto es inscrito en diferentes relaciones e interferencias al servicio de los juegos de verdad (Foucault, 1994: 123-124).

Por su parte, Derrida, que, con algunas diferencias ${ }^{2}$, coincide con Foucault, considera que no existe el lenguaje, sino los lenguajes, cuyo entrecruzamiento "coloca todo significado en citación diferencial" (Derrida, 1997: 9-10) y lo aboca a numerosas interpretaciones, a una continua diseminación. Con su crítica del pensamiento logocéntrico occidental, emprende la deconstrucción de la dicotomía habla y escritura,

\footnotetext{
${ }^{2}$ Los dos filósofos presentan un modo distinto de responder a la alteridad y a la imposibilidad del sujeto único: para Derrida uno no puede apropiarse del discurso y del nombre de otro sin desapropiarse de sí mismo, sin establecer con él cierta alianza. Para Foucault, por el contrario, uno no puede apropiarse de otro sin imponerle el propio discurso y el propio nombre, pero esa violencia también ha de ejercerla consigo mismo, puesto que la pluralidad de fuerzas en conflicto es infinita y borra constantemente el límite entre lo exterior y lo interior. Si uno no puede ser nunca sujeto único es por encontrarse desdoblado, pluralizado, ya sea comprometido con los otros y consigo mismo como un otro (Derrida), ya sea, en Foucault, por estar enfrentado con los otros y consigo mismo como un otro (Campillo Meseguer, 2001: 146).
} 
en un gesto que, considerado ya feminista (Bennington y Derrida, 1994: 236), ha influido, junto a la revisión del psicoanálisis lacaniano, en las pensadoras del feminismo francés de la diferencia (Moi, 1995: 112179; Eagleton, 1996: 284-338). Así, Julia Kristeva, distanciándose del esencialismo, estudia las formas de escritura que se apartan del orden simbólico vigente (la de la mujer, la del poeta vanguardista o la del místico) y rechaza una definición de la feminidad al considerar que no hay una identidad sexual fija. Por otro lado, Luce Irigaray y Hélène Cixous afirman que las mujeres deben representarse al margen del orden predominante. La primera propone un parler femme a través del que se revele la sexualidad femenina. Cixous habla de una écriture féminine que, entendida como différance (en el sentido derridiano), combata la lógica falogocéntrica y el sistema binario y que, vinculada al período preedípico de la vida, podrían practicar tanto hombres como mujeres.

Aunque pudiera parecer que las teorías postestructuralistas o postmodernas corren el riesgo de caer en cierto relativismo al concebir el sujeto como una invención lingüística en el marco de las relaciones sociales, y por tanto de las relaciones de dominio — de ahí que se muestren recelosas ante cualquier forma de identidad, cuya desaparición o diseminación privilegian-, no cabe duda de que han dado a conocer que la identidad personal puede ser, como defiende Campillo Meseguer (2001: 227), "una invención del propio sujeto, precisamente la invención de sí mismo como sujeto libre y responsable".

En la misma dirección apunta la investigación, desde un enfoque sociohistórico, de Almudena Hernando. Su estudio La fantasía de la individualidad profundiza en las normas que, basadas en la disociación razón-emoción, han servido para la construcción diferenciada de hombres y mujeres, sobre la que se fundamenta la identidad individualizada masculina, a la que denomina identidad dependiente (Hernando, 2012: 148), referida a la negación, al menos inconsciente, por parte de los varones, del vínculo emocional que los une al grupo. Para suplir esa necesidad, las mujeres han tenido que mantener una identidad menos individualizada, denominada identidad relacional (Hernando, 2012: 65-84).

Como sabemos, el poder implica algún grado de individualización, al tiempo que exige cosificar aquello sobre lo que se ejerce, de tal manera que se asume una posición de sujeto en la que el otro se convierte en objeto. Pero también exige objetivar el mundo por la razón y distanciarse 
de las emociones, un proceso que culmina en el pensamiento ilustrado con el discurso que legitima el mito de la razón y la ciencia (Hernando, 2012: 85-88), al que, al ser crucial para que seamos admitidos en los circuitos de poder, contribuyen tanto hombres como mujeres individualizados desde la Modernidad. Sin embargo, la seguridad basada exclusivamente en los mecanismos racionales (la identidad dependiente) ocasiona también conflictos que ellas han reconocido, pero que el discurso patriarcal invisibiliza (Hernando, 2012: 99). Por eso Almudena Hernando apuesta por una sociedad en la que cualquiera de los dos sexos pueda desarrollar, en mayor o menor grado, cualquiera de las dos identidades (relacional o individualizada) en aras de una verdadera individualidad independiente de las personas (Hernando, 2012: 169), un logro que aún no está en el horizonte cuando Marga Gil Roësset vierte sus emociones y sentimientos en una escritura desgarrada y abierta, en la que nos detendremos, después de repasar las características del género donde se enmarca.

\section{EL DIARIO COMO SUBGÉNERO AUTOBIOGRÁFICO}

La autobiografía, en la definición propuesta por Lejeune en 1975, supone, al igual que los demás géneros de la literatura íntima, una identidad de nombre entre el autor, el narrador y el personaje (Lejeune, 1994: 61), que se sanciona en un pacto autobiográfico con el lector ${ }^{3}$ (Lejeune, 1994: 64). No obstante, en tanto escritura, implica una construcción que participa al mismo tiempo del discurso verídico y del literario (Lejeune, 1994: 137). Incluso el propio estudioso francés, en su trabajo de 1986, Moi aussi, llega a reconocer que "decir la verdad sobre uno mismo [...] es una utopía", aunque después precisa: "por muy imposible que resulte la autobiografía, ello no impide en absoluto existir" (Lejeune, 1994: 142).

Más receloso se muestra Paul de Man (1991: 118), cuya teoría anima, en nuestro ámbito, el trabajo de Nora Catelli (1991). Para el teórico deconstruccionista, en la medida en que "el lenguaje es figura (o metáfora, o prosopopeya)", la autobiografía supone la realización de un tropo, por lo

\footnotetext{
${ }^{3}$ A este respecto, Campillo Meseguer (2001: 170) señala que la escritura, como práctica social, produce unos efectos de autor - la función interna en el texto tras la cual se esconde el individual real- en el escritor y en el lector, que determinan el modo en que ha de ser leído el texto. Para los conceptos de autor y de nombre propio, véase Campillo Meseguer (2001: 161-189 y 149-160 respectivamente).
} 
que se hace imposible la verdad sobre la escritura del yo.

Esta discrepancia teórica es una manifestación del debate planteado en el seno del Postestructuralismo, que, frente al racionalismo cartesiano, cuestionaba el valor ontológico de la verdad, al mismo tiempo que subrayaba la fragmentación del sujeto, lo que sin duda ha motivado el interés por el estudio, desde diferentes enfoques, de la autobiografía ${ }^{4}$ y ha encontrado un campo propicio para el de autoría femenina, especialmente en países como Francia, con más larga tradición autobiográfica que el nuestro (Romera Pintor, 2018).

A pesar de que algunos de estos planteamientos difieren de la propuesta de Lejeune, no existe un gran desacuerdo al abordar el hecho autobiográfico (Pozuelo Yvancos, 1993: 202 y 2006), ya que el discurso del yo puede ser ficcional, pero no impide que sea leído como veraz. Es la formulación que, desde una perspectiva pragmática, presenta en 1976 Elisabeth Bruss (1991: 65), quien sostiene que la autobiografía alcanza pleno significado dentro de los sistemas simbólicos de la literatura y la cultura que, como tales, se rigen por reglas intersubjetivas. Una de ellas, necesaria para que el acto de habla autobiográfico se cumpla, es el valor de verdad de lo que el autobiógrafo relata y que se espera sea aceptado como verídico por parte del lector (Bruss, 1991: 67). No se hallaba lejos de Lejeune, con el que coincide en el requisito de la identidad de autor, narrador y personaje, cuando un año antes el autor francés defendía que "el género autobiográfico es un género contractual” (Lejeune, 1994: 85) que precisaba un pacto de lectura.

Nos referimos a un discurso que se construye siguiendo una coherencia entre lo vivido y la interpretación que de ello hace el autor (Fernández Prieto, 1994: 126-127), porque la autobiografía, según Darío Villanueva (1991: 108), "posee virtualidad creativa, más que referencial". En esta tarea, el autobiógrafo experimenta un desdoblamiento y pasa de la condición de sujeto a la de objeto y este "es la identidad que previamente

${ }^{4}$ Prueba de ello es, en nuestro país, la aparición de las revistas Intramuros (Buenos Aires / Madrid, 1995) y Boletín de la Unidad de Estudios Biográficos (Universidad de Barcelona, 1996), dirigida por Anna Caballé, que se ocupan de la autobiografía y de los géneros biográficos en general. O la tarea realizada por José Romera Castillo (2010), ya sea como editor de actas de Seminarios internacionales (Romera, 1993, 1998, 2000) o como autor de un estudio (Romera, 2006), por citar algunos ejemplos. Pero también Loureiro (1991a, 1991b y 1994), Caballé (1995), Tortosa (2001), Balaguer Pascual (2001), C. Fernández y M. A. Hermosilla (2004) o Pozuelo Yvancos (2006). 
se ha construido en la escritura" (Castilla del Pino, 1989: 149), de modo que la construcción del yo tiene lugar a posteriori, en un proceso realizado por el sujeto con el fin de lograr el mayor éxito para sí mismo (Castilla del Pino, 1996: 16-17).

Ahora bien, estas características generales del género autobiográfico no se dan exactamente en el diario, donde el autor o autora no conoce el final de los sucesos de los que habla, sino que practica una escritura abierta, con unos rasgos propios que, en la modalidad concreta del diario íntimo y de mujer, trataremos de precisar.

Corresponde a Alain Girard, en su ensayo clásico de 1963, haber fijado las características de la escritura diarística ${ }^{5}$ : se escribe día a día, sin una determinada estructura, el pronombre personal de primera persona rige el discurso, posee carácter secreto - hasta el siglo XX no se destina a la publicación-, se centra en la faceta privada de su autor, que constituye el centro de la observación, y se extiende por un determinado lapso de tiempo (Girard, 1986: 3-5).

Por lo que se refiere al diario íntimo, su origen se encuentra en Francia, con las confesiones de Rousseau, halla un campo favorable en la expresión de la subjetividad romántica y se desarrolla en el siguiente cambio de siglo, cuando la industrialización contribuye a la soledad del ser humano, que se repliega sobre sí mismo (Girard, 1986: XII-XIV). Sin embargo, en España, con la excepción del diario de Unamuno, no se cultivará prácticamente hasta el siglo XX, como ha mostrado en su estudio Danielle Corrado (2000: 257-348), que, además, reúne una serie de elementos formales, funcionales y de publicación para una poética de este subgénero.

Pero el diario se caracteriza también por la monotonía generada por la repetición de lo cotidiano, a lo que se intenta dar una forma literaria (Bou, 1996: 124), porque, según Béatrice Didier (1996: 44), puede convertirse en un ejercicio de escritura donde caben diversos materiales (Bou, 1996: 39), lo que lo convierte en un género literario muy vulnerable, bien sea por las modificaciones que, en la publicación, puede introducir el

\footnotetext{
${ }^{5} \mathrm{El}$ diario comparte sus peculiaridades con otros subgéneros autobiográficos, sobre todo con el dietario, del que se diferencia por el predominio de lo afectivo y la cotidianidad - recuerda Laura Freixas (1996: 12-13) — y la carta, de la que se distingue por el tipo de relación con el otro (Didier, 1996: 43), que, en el diario está ausente, porque se centra en el mundo personal del autor y, en el diario íntimo, en su estado anímico (Girard, 1986: 4-5).
} 
autor o autora, las que se deben a condicionantes editoriales, o bien, en las ediciones póstumas, como el diario de Marga, por la censura que podría ejercer la propia familia.

En todo caso, el diario, como la autobiografía, exige la identidad del narrador y del personaje (Corrado, 2000: 7), pero es el tipo más narcisista e individualista de la escritura autobiográfica. Si en esta la identificación de autor-narrador-personaje requiere, como hemos señalado, un pacto con el lector, en el diario, aparte de esa identificación, el emisor se desdobla en receptor, ya que, en principio, no está destinado a publicarse. Cuando esto sucede, el diario vuelve a integrarse en un proceso comunicativo que apela a un receptor (Romera Castillo, 2006: 344). Es lo que sucede con frecuencia en el diario íntimo, en cuya especificidad conviene detenerse.

\subsection{La intimidad en el diario}

El diario íntimo es una modalidad de difícil definición, que ha motivado a veces la preferencia por el adjetivo personal, de uso más amplio (Braud, 2006: 9). La primera acepción del diccionario académico recoge el significado de íntimo como "lo más interior o interno", de modo que el diario íntimo está vinculado a la noción de interioridad y posee una intención no divulgativa (Corrado, 2000: 7), que no tiene que ver con la naturaleza de su contenido — precisa Danielle Corrado (2000: 327)—, sino con la falta de reconocimiento de la institución literaria. Creado en 1882 para la publicación parcial del diario de Henri-Frédéric Amiel, el término, en su cuarta acepción, alude a lo relativo a la intimidad, que, a su vez, expresa la "zona espiritual íntima y reservada de una persona". De este modo, puede relacionarse, por un lado, con lo religioso: recordemos el antecedente, en el siglo IV, de las Confesiones de San Agustín, su autobiografía de conversión, y en nuestro país, por ejemplo, el Libro de la vida de Santa Teresa o la obra autobiográfica de San Ignacio de Loyola (Corrado, 2000: 25-32), lo que ha llevado a Alain Girard (1986: X) a hablar del diario como un "examen de conciencia, laicizado". Por otro, el vocablo está unido al concepto de persona, que, si bien parece natural, es construido, complejo y determinado culturalmente (Girard, 1986: XVII-XVIII). En el siglo XX en concreto, el cambio de valores que supuso la revolución industrial condujo al ser humano a refugiarse en el espacio privado, donde toma conciencia de sí mismo, como refleja el diario íntimo, sin embargo, 
lo privado no se identifica con lo íntimo. Para explicarlo, acudiremos a la teoría del sujeto de Castilla del Pino (2001: 392), que lo concibe como "el sistema del organismo mediante el cual se construyen yoes adecuados para una secuencia de actuaciones en la realidad". Estas, a diferencia de las actividades - el tic, las manifestaciones epilépticas, etc.-, son siempre intencionales y en ese supuesto se basa la interacción con los otros (Castilla del Pino, 2001: 390). Pero el sujeto no solo realiza actuaciones de un yo, sino que prepara, de acuerdo con los intervinientes, un escenario, es decir, el contexto en el que tienen lugar las actuaciones humanas, según el cual estas pueden ser íntimas, privadas o públicas. Aunque el carácter de representación es evidente en las actuaciones públicas, también lo son en las privadas, las que se llevan a cabo a solas o ante alguien muy cercano, y en las íntimas, las que tienen lugar en nuestro imaginario, o sea, "las actuaciones que reservamos para nuestra intimidad". Por tanto, lo imaginado no puede mostrarse, pero sí comunicarse, verbalizarse (Castilla del Pino, 1996: 18-19).

En este mismo sentido se sitúa el trabajo de Celia Fernández. Después de afirmar que el lenguaje no puede reproducir una realidad psíquica, sino que la crea gracias a su potencia performativa, se refiere al diario íntimo, que, en cada caso, "ensaya, explícita o implícitamente, una teoría y una retórica de la intimidad” (Fernández Prieto, 2015: 62). Y a continuación dedica el último apartado del artículo a este subgénero autobiográfico, del que ofrece algunas muestras concretas. Es la línea que siguen actualmente otros trabajos que se ocupan de la escritura diarística (Luque Amo, 2016 y 2018).

Así pues, la intimidad es el ámbito de la libertad de actuación donde pueden desarrollarse distintos yoes, a veces inimaginables, pero al mismo tiempo se ve influido también por las normas dictadas por el poder sociopolítico o religioso en cada momento y que ejercen un mecanismo de autocontrol en ese sujeto pluriforme. De ahí que este se vea obligado a realizar una tarea de construcción de lo íntimo en la que, ensayando procedimientos que escapen a la observabilidad, termine por resguardar sus deseos en la vida mental o la fantasía (Castilla del Pino, 1996: 25-28), un proceso que adquiere mayor complejidad, como veremos seguidamente, en las mujeres cuando deciden dar rienda suelta a la loca de la casa, por citar el título de la obra de Rosa Montero, donde, inspirándose en Santa Teresa, aborda las razones del literato para enfrentarse a los fantasmas de 
la imaginación.

\subsection{Escritura femenina y diario}

Para las escritoras, plasmar sus inquietudes más profundas en un texto que va a ser publicado conlleva, como asevera Noël M. Valis (1991: 36), exponer su reputación, "su identidad genérica como construcción cultural de la feminidad". Aunque ya hemos señalado que el diario es una creación verbal, al transformarse la actuación íntima en pública, los lectores, que se rigen por el código de lo íntimo, lo perciben como exhibición. Por eso las autoras prefieren reflejar los aspectos de su intimidad en la ficción (Freixas, 2004: 118) y reservan lo más personal para el diario, escrito en secreto y sin ánimo de publicarlo. Pero, además, las características de este subgénero autobiográfico se adecuan bien a las oscilaciones emocionales del día a día - porque la dimensión temporal es un factor esencial de la autopercepción (Corrado, 2000: 13) - y a la anotación de la actividad de la conciencia en un discurso suelto y deshilvanado sin las ataduras de los géneros literarios canónicos.

Sin embargo, a pesar de que ha sido frecuente, desde el pasado hasta hoy, la práctica, por parte de las mujeres, de la escritura diarística, al igual que de la epistolar (Planté, 1998; Torras, 2001; Díaz y Siess, 2006), lo que ha estimulado la publicación, en las últimas décadas, de autobiografías femeninas (Romera Castillo, 2006: 127-141), pocas han sido las que decidieron llevar a la imprenta un texto que pertenecía a un género de cultivo mayoritariamente femenino y que, quizás por ello, poseía escaso valor institucional, aunque como reconoce Laura Freixas (2015: 34), ha dejado su huella en la introspección narrativa de la gran literatura y ha influido en el auge actual de las obras autobiográficas en general (Romera Castillo, 1993: 421-505) y, aunque en menor grado, del diario en particular (Romera Castillo, 2006: 367-379), en cuyo mercado editorial predominan ahora los títulos de autoría masculina.

En el límite de estas páginas no podemos profundizar en los rasgos que diferencian los diarios de hombres y mujeres, más centrados los primeros, por lo común, en la tarea como sujetos de una actividad pública - de ahí que se haya afirmado que, si bien existe autobiografía en nuestro país de los siglos XVII al XIX, falta intimidad (Freixas, 1996: 7)—, pero el diario íntimo, por sus características, puede considerarse, según la 
denominación de Hélène Cixous (1995: 61), una escritura femenina, que no se refiere a la firma de un autor o autora, sino al estilo.

Una idea similar mantiene Nora Catelli (1996) cuando habla de la posición femenina del diario íntimo. Partiendo del ambiguo sentido etimológico de intimidad, el término, aparte de aludir a una relación estrecha, se relaciona con intimidación, es decir, la incorporación del temor en un sujeto (Catelli, 1996: 88-89), que, en las mujeres diaristas, supone "una doble marginalidad" (Catelli, 1996: 87). Si en el pasado escribir significaba, como en Santa Teresa, encerrarse en la celda con los demonios, en la Modernidad, estos, lejos de desaparecer, siguen estando presentes, ahora por motivos laicos, e incluso se funden con el sujeto (Catelli, 1996: 93) en el espacio doméstico. Por tanto las personas - varones o mujeresque se encierran con los fantasmas que intiman adoptan una posición femenina, porque, quebrando las identidades estáticas, van al encuentro del goce, de la jouissance lacaniana (Catelli, 1996: 96-97).

Es la salida, que lleva a cabo la autora que no desea convertirse, según la expresión de Sidonie Smith (1991: 100), en una mujer fálica, ya que el sujeto autobiográfico no es neutro, sino que se ha establecido como masculino y la mujer, al haber sido privada tradicionalmente de la vida pública, encuentra obstáculos para reflejar su yo en la literatura, salvo que hable la lengua patriarcal y se adapte a los códigos imperantes en los que se fundamenta la identidad. Por el contrario, el otro camino para rehuir el discurso falogocéntrico es situarse en la genealogía materna, en la línea de Cixous, Irigaray y Kristeva, y ejercitar una escritura que está, "como la voz de la madre, fuera del tiempo" y que es "plural, fluida, bisexual, descentrada, no-logocéntrica" (Smith, 1991: 102-103).

A pesar de que la profesora americana reconoce que las teorías francesas de la diferencia pueden caer en otra clase de esencialismo, al proponer una teoría en torno a lo femenino que subvierte el orden simbólico establecido, la autobiógrafa podrá comprender y superar la ficción de una ideología basada en la separación entre los sexos y crear otro tipo de subjetividad (Smith, 1991: 103). Es también lo que defienden otras teóricas feministas, como Judith Butler, cuando denuncia que la identidad no está asociada a la persona, sino a las normas socialmente instituidas (Butler, 2001: 50) y se refiere a la mujer como "un término en proceso" (Butler,

${ }^{6}$ Para la jouissance en las poetas españolas de hoy, véase M. Ángeles Hermosilla (2017). 
2001: 66-67), o Rosi Braidotti (1994: 31), al proponer una subjetividad nómade, que define como la transgresión de las convenciones establecidas.

Se trata asimismo de la idea que, basándonos en los postulados postestructuralistas, planteábamos en el primer apartado de este trabajo, con el fin de ubicar el discurso abierto de nuestra diarista, del que nos ocuparemos seguidamente.

\section{EL DIARIO DE MARGA}

Todo lo expuesto hasta aquí encuentra cabal plasmación en el diario que escribió Marga Gil Roësset desde el 22 de julio de 1932, fecha en que puso fin a su vida, cuando contaba con veinticuatro años, a causa del amor no correspondido a Juan Ramón Jiménez.

Se trata de un texto de cuarenta y siete folios, publicado por primera vez en 2015, con el título Marga, siguiendo la edición preparada por el propio poeta ${ }^{7}$, cuyo peculiar uso ortográfico adopta, gracias a la escritora y fotógrafa Marga Clark, sobrina de la autora, de la que realiza una ajustada semblanza, y de Carmen Hernández-Pinzón, representante de los herederos del Nobel español, a quien debemos el prólogo, cumpliendo así el encargo de su padre y la voluntad de Juan Ramón, que, conmocionado por la tragedia ${ }^{8}$, escribió:

Si pensaste al morir que ibas a ser bien recordada, no te equivocaste, Marga. Acaso te recordaremos pocos, pero nuestro recuerdo te será fácil y firme. No te olvidaremos, no te olvidaré nunca. Que hayas encontrado bajo la tierra el descanso y el sueño, el gusto que no encontraste sobre la tierra. Descansa en paz, en la paz que no supimos darte, Marga bien querida (Jiménez, 2015: 82).

Más tarde dispuso en una carpeta de piel amarilla, con los primeros versos de La soledad sonora grabados en oro en el reverso, todo el material

\footnotetext{
${ }^{7}$ En lo sucesivo las citas del diario y de otros textos que contiene el libro se realizarán por esta edición (Jiménez, 2015).

${ }^{8}$ Sobre el impacto emocional que supuso el suicidio de Marga en el poeta de Moguer y en su mujer, véase la introducción de Carmen Hernández-Pinzón (Jiménez, 2015: 10), el recuerdo familiar de Marga Clark (Jiménez, 2015: 21) y las anotaciones de los días posteriores al infortunio realizadas por Juan Guerrero Ruiz (1999: 36-37, 38 y 39), buen amigo de Juan Ramón.
} 
relacionado con Marga: el diario que ella le entregó el mismo día de su muerte, las cartas de despedida que dirigió a sus padres, a su hermana Consuelo y a Zenobia, junto a poemas, textos y anotaciones del poeta y de su esposa, que tenía la intención de escribir una Historia de Marga, de la que, se recogen fragmentos traducidos del inglés para esta edición por Carmen Hernández-Pinzón. Todo ello, además de portadas, portadillas, notas de Marga, fotografías, recortes de prensa y reproducciones facsimilares, pensaba publicarlo en un libro Juan Ramón a finales de 1932, pero diversos avatares, de los que se da cuenta en el prólogo, impidieron que se llevara a término un proyecto que, avalado por el gran poeta, hubiera redundado en el reconocimiento de Marga Gil Roësset.

\subsection{La autora}

Perteneciente a una familia de la alta burguesía, en la que había presencia de mujeres artistas (Capdevila-Argüelles, 2013), recibió, al igual que su hermana, una amplia formación, sobre todo en arte, música e idiomas, de la que se encargaba su madre, una mujer culta y sensible, a la que las hijas, y especialmente Marga, estaban muy unidas. Con este estímulo, a los siete años escribió e ilustró el cuento La niña curiosa y a los doce y trece años realizó, respectivamente, las ilustraciones de los cuentos de su hermana El niño de oro y Rose des Bois. Este último, en francés, fue publicado en París y reseñado en Le Figaro (Balló, 2018: 66).

Años más tarde se publicó póstumamente el libro Canciones de niños, escrito en español y en francés por su hermana Consuelo y con libreto musical de su cuñado, cuya cubierta presentaba tres dibujos de Marga, recogidos en el apéndice de su diario, que fueron seleccionado por Juan Ramón, uno de los cuales, Las cerezas, guarda tal semejanza con el de Le petit prince que, según Marga Clark, se ha especulado con la posibilidad de que Saint-Exupéry se hubiera inspirado en él (Jiménez, 2015: 21-22).

Cuando Juan Ramón y su mujer conocen a las hermanas, que sentían gran admiración por Zenobia, como constatan la prologuista y la sobrina de Marga (Jiménez, 2015: 8 y 19), quedan impresionados por el cuento $E l$ niño de oro y enseguida visitan el taller de nuestra autora, que empieza a 
destacar en la escultura y cuya obra Adán y $E v a^{9}$ había sido aplaudida por las pintoras del momento y elogiada por la crítica en la revista La Esfera el 17 de agosto de 1930. En ese número, ilustrado con fotografías de otras dos esculturas suyas, se ofrece un amplio reportaje sobre la artista, que contaba solo con veintidós años. No fue el único: en otro, publicado el 13 de julio del mismo año en Crónica, después de la entrevista realizada a Marga por Rosa Arciniega el 13 de julio de ese mismo año con motivo de la muestra del grupo escultórico Adán y Eva en la Exposición Nacional de Bellas Artes, la entrevistada hablaba de la creación y de su concepción del amor, las dos claves para la adecuada comprensión de su escritura diarística. Con respecto a su tarea artística afirmaba:

Yo intento siempre operar sobre mis esculturas de dentro afuera. Es decir, trato de esculpir más las ideas que las personas [...] llevan el esfuerzo de querer manifestar su interior (Jiménez, 2015: 19).

Se advierte así el empeño de la artista por plasmar la interioridad, el lado íntimo en una labor creativa personalísima que, en palabras del crítico José Francés, "no debe nada a profesores ni maestros"10 y, para subrayar la maestría de su técnica, utiliza el género gramatical masculino: "Se está pues en presencia de un artista verdadero" (Jiménez, 2015: 19), como era habitual en la época ${ }^{11}$. El mismo Juan Ramón, antes de su encuentro con ella, había imaginado que era rubia, como Consuelo, que respondía más al estereotipo de la feminidad, y la describe con "una actitud de energía, brazos musculosos, morenos, heridos siempre de su oficio duro [...] Amarga. Persa. Fuerte, viril” (Jiménez, 2015: 81). De este modo se pone

\footnotetext{
${ }^{9}$ A pesar de que Marga destruyó el día de su muerte parte de sus obras, la exposición que, comisariada por Ana Serrano, organizó el Círculo de Bellas Artes de Madrid en el año 2000 logró reunir dieciséis esculturas suyas, ochenta dibujos y acuarelas, aparte de dos fotografías, cinco objetos personales y los cuentos de su hermana que ella ilustró (Jiménez, 2015: 22).

${ }^{10} \mathrm{La}$ madre de la joven escultora, que a los quince años practicaba el oficio con una dedicación poco común para su edad, mostró algunas obras de su hija al escultor Victorio Macho para que la tutelara, pero, asombrado por la destreza empleada, prefirió no inmiscuirse en su capacidad creativa, según explica Marga Clark (Jiménez, 2015: 18).

${ }^{11}$ Para referirse al talento poético de Rosalía de Castro, Azorín acusaba de ignorancia a la crítica que no reparaba en "uno de los más delicados, de los más intensos y originales poetas que ha producido España", cita que se reproducía décadas después en los manuales de literatura para bachillerato (Lázaro Carreter y Correa Calderón, 1971: 83).
} 
de manifiesto la ausencia de un sujeto femenino en el discurso artístico oficial, años antes de que esa constatación se formulara en las teorías feministas y del postestructuralismo.

En cuanto a su idea del amor y el matrimonio, Marga declaraba:

No creo en el amor simultáneo, de dos corazones [...] Yo, por ejemplo, puedo enamorarme de un hombre sencillamente porque me gusta; pero me parece dificil que él al mismo tiempo se enamore de mí, completando asi el amor. Me parece que en esto hay siempre un sacrificio [...] Yo como no espero hallarle, tampoco pienso casarme (Balló, 2018: 69).

Con esta actitud, parecía contestar a la realidad del momento histórico que le tocó vivir y que, en 1931, denunció la ministra española Federica Montseny, en su libro El problema de los sexos. Matrimonio, unión libre y amor sin convivencia, reeditado en el exilio diecisiete años más tarde, donde aseguraba: "una mujer que trabaja, estudia, cura, enseña o escribe para los hombres es compleja; desde luego poco femenina" (Capdevila-Argüelles, 2017: 37).

También el poeta de Moguer, que había aconsejado a Marga viajar a París o Londres para completar su formación (Guerrero Ruiz, 1999: 41), reconocía la dificultad que tenía esta para realizar su ideal y desarrollarse como artista:

Si Marga hubiera tenido tiempo, espacio para soñar, hubiese suplido con aquellas alas de que me hablaba, la realidad visible [...] Prefirió la realidad invisible. [...] Acaso creyó que no vivía a su gusto. ¿Quién puede hacer su gusto! ¿Quizás no podía realizar su obra! ¿Quién puede realizar su obra? Pero ella no quería términos medios (Jiménez, 2015: 85-86).

\subsection{El texto diarístico}

Pero es la propia escultora quien abiertamente expresa en el diario su deseo de llevar a cabo su quehacer artístico al lado del hombre amado:

... Ideal ... el amor de dos personas ... eso sí ... dos únicas personas 
vivido en una atmósfera de trabajo intenso ...

... Ya tú ves, alguna tarde que me he quedado en tu casa trabajando

... y ... tú también ... esa satisfacción del trabajo a gusto ... yo en el mío ... saberte a ti en el tuyo ... es un lazo de unión tan sólido ...

Cada uno en su obra ... y ahora y luego ... irse uno junto al otro ... y así ... (Jiménez, 2015: 38).

Y enseguida surge la declaración amorosa ${ }^{12}$, fruto de una afinidad que cree compartida:

... Qué sonata ... iqué sonata! qué maravilla ... qué bien me he sentido

... jcómo te quiero!

... SI tú, espontáneamente, me dieras un beso ... y me atrajeras ... asi ... estrechamente ... dejándome ... oir en tu pecho latirte el corazón ... y un poco también la plata de tu voz ...

... Sería glorioso ... luego de esa plenitud iqué contenta! (Jiménez, 2015: 38-39).

Sin embargo, esta expresión entrecortada, con frases en redonda, según el subrayado en lápiz rojo realizado por el poeta (Jiménez, 2015: 15), que da paso al sentimiento, representado en un discurso metafórico, choca con la realidad, basada en lo racional, del destinatario del mensaje, a lo que la escritora también alude:

Claro... tú me ves exactamente y es natural ya que tú eres la razón ... la fase de mi vida sentimental ... donde digo adiós a las cosas ... ... Pero realmente yo no soy así ... (Jiménez, 2015: 38).

Así, de acuerdo con la tarea de Castilla del Pino que sintetizamos en el apartado correspondiente a la intimidad, el yo de la diarista, que se presenta subrayado en el texto, constreñido por las normas psicosociales, se ve obligado a recluirse en la vida mental:

\footnotetext{
${ }^{12}$ Las expresiones de amor, a modo de ritornello, son recurrentes en el diario (Jiménez, 2015: 43, $44,55,56,58,61,72)$.
} 
... Pero tengo bastante miedo ... me parece que tendré que morirme triste ... sin beso ... ni corazón ... ni voz de plata ... ni versos ... jay! Imaginar ... siempre imaginar ... y yo no sé si en ese momento sabré engañarme aún ... o me moriré de pena (Jiménez, 2015: 39).

En el mismo sentido se manifiesta más adelante, en un enunciado lleno de sensualidad, donde el subrayado confirma el motivo de ese refugio en la imaginación:

Muy tempranito ... como es primavera y de gloria madrugar ... me iría al campo contigo ... claro que, como contigo de verdad ... en persona, no sería posible ... contigo imajinativamente ...

... Y ... qué mañana de empaparme de ... campo nuevo ... y de ti ... flores ... y tú ... tomillo ... versos ... flores ... vida ... ivida! (Jiménez, 2015: 63).

También se advierte en otro lugar, de modo aún más elocuente, que parece preludiar la idea de que un grado de error, de delirio, es a veces necesario para vivir (Castilla del Pino, 1998):

QUÉ razón tiene el que ha dicho ... que "donde no hay comprensión ... no hay amor" ... no me cabe duda, el ¿amor? tuyo ya no es ... pero jacaso ha sido nunca!

En fin, yo lo imajiné y fui feliz ... querría poder seguir con esa ilusión este tiempo aún ... pero la realidad, con sus crudezas disonantes no te deja situarte en el mundo de lo ideal ... único posible para mí ... (Jiménez, 2015: 69).

En ambos casos la vivencia del amor va unida a la realización de la obra. En el que acabamos de transcribir esa conjunción significa la plenitud:

... Juan Ramón ... tú sabes lo que es amor - lo has escrito tan bien -, lo has debido sentir de tantas maneras ... Yo antes suponía ... ahora sé ... entiendo que es lo mejor de la vida ... amor que es ideal ... deseo ... amor de un hombre y una mujer ... amor a la obra ... [...] ... tu amor ... al ser ... lo entró todo ... como el mar lo entra 
todo ...

... Por él, contigo ... por ti ... todo es vivo, encendido ... obra ... vida ... ¡todo! (Jiménez, 2015: 69).

Nótese la escisión entre sentimiento y razón, cuyos términos, al figurar subrayados, como el referido a la obra, alcanzan similar relevancia.

El otro ejemplo es asimismo significativo: tras el pespunteado nominal que apelaba a los sentidos, y al placer de la vida, surge la referencia al trabajo:

... Y ... luego, a trabajar ... tú y yo ... mirarte ahora ... y luego ... $y$ luego ... irte moldeando con mis manos ;ay! yo a ti ... como una madre ¡no! como una ¿novia? ... ¡como una enamorada! ...

Acaso ... acaso no es eso lo mejor ... ... Juan Ramón, fuego, nardo, ... vida ... espíritu ... esta cabeza tuya ... nunca la acabaría ... porque cada vez que te miro ... veo algo nuevo que aun antes no era ... o no veía ... y es que cada día te renuevas ... y me renuevo ... (Jiménez, 2015: 63).

La diarista habla aquí de su proyecto de esculpir el busto de Juan Ramón, que no llegó a realizar, de llegar a ser sujeto de la creación de una obra que tuviera como objeto al ser amado, como ya había hecho con la cabeza de Zenobia, trabajando en casa del matrimonio durante unos meses, que sirvieron para estrechar la amistad con la pareja de escritores y en los que va enamorándose del poeta, quizás porque ese amor se adecuaba al modelo de relación de las parejas intelectuales del cambio de siglo (Siso y Pla, 2016: 1083).

Pero ¿cómo invertir el orden vigente que reservaba a la mujer el papel de amada y de objeto en el campo artístico? Es un obstáculo que se deduce de las palabras de Marga y que ella lleva hasta sus últimas consecuencias:

... Ilusión matada ... muerte de lo realizable ... irrealizable ... ya ... más triste aún que la otra (muerte) aunque tiene en mí prólogo y epílogo ... y la otra ... sólo es prólogo ... jcreo!

... Ya ... a qué esperar, si así ya no puede ser ... ja qué esperar!... ... Porque cuando vengan yo no puedo seguir ... mi espiritu no tiene 
elasticidad para emprender un trabajo ... ... tan lejano de mí ahora ... para vivir a su antojo (de ellos) ... ya que lo que yo únicamente siento ... lo tengo prohibido ... (Jiménez, 2015: 63).

Como el yo íntimo no puede mostrarse, la única salida es la verbalización de los deseos más profundos en un diario que, como si se tratara de la entrega de la propia persona, Marga pone en manos de Juan Ramón horas antes de su muerte. Aunque el suicidio ha formado parte de la historia literaria desde la antigüedad (Zambrano Carballo et alii, 2006) y alcanzó su máxima expresión en el Romanticismo, el problema es más complejo en el caso de nuestra autora, porque, más allá de la exaltación de unos sentimientos que no encuentran su realización en este mundo, supone una creación verbal de la intimidad en la que el sujeto desaparece, pero que halla su cumplimiento en un receptor que, a través de la lectura de un texto fragmentado, trufado de frases inacabadas, casi indescifrables, subrayados, con gran profusión de puntos suspensivos, realiza una verdadera labor de construcción.

En definitiva, nos encontramos con una escritura, fluida, descentrada, asociada a la madre pre-edípica, que rompe el binarismo hombre/mujer o razón/sentimiento, es decir, una escritura femenina, en el sentido de Hélène Cixous. En ella aflora una retórica del silencio que en ocasiones, como en otras obras de escritoras (Hermosilla, 2017), toca la jouissance, según se observa en el escueto texto que abre el diario: "Todo lo bello ... porque tú sabes mirarlo ... agradecido se te entra ... ... y te hace a ti, más bello ... jaún!” (Jiménez, 2015: 33). De ahí la utilización de un estilo con predominio nominal para transmitir, como en el balbuceo sanjuanista, la pasión amorosa, que se expresa con resonancias líricas:

Tu voz ...

... tu sonrisa

tus ojos ...

... yo ... qué dicha ... alguna

vez ..., me has hablado ...

... y sonreído, ... y ...

... mirado ... vida ...

Tú, a mí ... y yo, cómo

no me habré muerto, entonces, 
... de contento.

lunes noche ... (Jiménez, 2015: 37).

Conviene señalar que, aunque el diario no tiene fecha, salvo el "Miércoles 22" (Jiménez, 2015: 34), de vez en cuando, como aquí, se indica el día de la semana (también en Jiménez, 2015: 62, 68,73) o, simplemente, se anota el final: "NOCHE última" (Jiménez, 2015: 74).

En otros momentos, el estilo sincopado deja traslucir la huella petrarquista y del amor cortés que, contraviniendo la herencia cultural, ensaya un sujeto femenino que realza su erotismo con subrayados y oraciones exclamativas:

... Estabas ... eres tan, no te enfades, comprende que soy artista... y claro, me fijo ... tan guapo, no, no es esa la palabra: ... sujestivo, persa ... ojos, qué ojos ... idios, qué ojos! ... nariz, boca, ilabios! ... dientes ... pómulos nobles ... espresión ...

... Todo tú ... desde todos los aspectos ... cómo me gustas, ;y cómo te quiero! (Jiménez, 2015: 61).

O bien, como es propio del diario íntimo (Braud, 2006: 82), el discurso logofágico se convierte en una escritura del cuerpo, que revela así el sufrimiento del yo:

He estado mala toda la noche y todo el día aún ... golpe ... taxi ... golpe ... ... no ... la idea ...

... En mi cabeza, la voz ... tu voz constante ... fue ... «te vas ... me parece muy bien»...

... Me trajisteis valeriana ... y rosas ... rosas ... rosas ...

Me encuentro confusa ... y misteriosa ... Cuando es tan claro ver todo ... hombre ... (Jiménez, 2015: 54).

De este modo, descubrimos un discurso donde con frecuencia aparece la antítesis — "confusa"/“claro" en el último ejemplo-, que se repite en otros textos: “... Con ser bueno ... eres injusto, ... y con ser sensitivo ... eres cruel ...” (Jiménez, 2015: 62), o en este: “... porque, lo 
mejor no puede ser ... todo me importa nada ... con ser quizás magnífico ... ¡no quiero nada porque quiero tanto"! (Jiménez, 2015: 69). Y asimismo la paradoja: "cómo / no me habré muerto, entonces, / ... de contento" (Jiménez, 2015: 37), o incluso “... querría no quererte tanto ... aunque mi única razón de ser ... es esa ... y también mi única razón de no ser ..." (Jiménez, 2015: 44). Son muestras de un sujeto histerizado que se construye fragmentariamente en la escritura diarística, desdoblándose en un personaje en el que no se reconoce:

... Si no fuera porque ... porque me he resignado ... porque miro la vida mía propia como una cosa fuera de yo ... que yo contemplo ... pero que no soy ... lloraría ... (Jiménez, 2015: 44).

También aquí: "Es que estoy loca ... claro ... y sé que no lo soy ... entonces ... ¡qué! ...” (Jiménez, 2015: 55). Pero cuya subjetividad se inscribe en el texto, como este, de significativo título:

\section{-Desequilibrio-}

La visión relativa mía ... visión de valores ... iqué extraordinaria! ... Pensando que si me muero ... no veré más tu obra ... no veré lo que sigue ... siento la muerte absurda.

... Si me dijeran ... aun tú muerta, su obra irá a ti ... entonces ... siilií, ;muerta ...! ....................

... Obra tuva ... cuerda mojada ... irrompible ... que me ata aquí ... a la vida ... de la vida al corazón ... de la vida a la cabeza ... de la vida ... no sé ... de la vida por el pecho, debajo de los brazos ... un lazo ... abrazo intenso ...

... iNo quieres la vida! ... isiibii! ;Ah! ... entonces ... ino quieres la muerte! ...

... La muerte ... iSílíĺ! entonces ... jentonces no quiero nada ... por quererlo todo! (Jiménez, 2015: 48).

Una vez más el discurso entrecortado se sustenta en elementos antitéticos, con una marcada intención expresiva, como demuestran los signos de admiración, el alargamiento vocálico, repetido dos veces - 
la última en mayúsculas - y el subrayado referido a la obra del poeta admirado, en la que el yo íntimo anhela disolverse.

La locura es un tema recurrente en la literatura de mujeres, tema al que estuvo dedicado el XII Congreso internacional del Grupo de investigación sevillano Escritoras y Escrituras (Martín Clavijo et alii, 2015). Basta recordar, en la época victoriana, a autoras como las hermanas Brontë, Janes Austen o Emily Dickinson, estudiadas por Sandra M. Gilbert y Susan Gubar (1998), que experimentaron el desajuste social en su entorno. $Y$ es que la simbiosis entre los conceptos de mujer y locura, arraigados en el lenguaje y las metáforas, dimana de la vinculación, en el patriarcado, con la irracionalidad, la naturaleza, el silencio y lo corporal, mientras que el hombre se relaciona con la racionalidad, la cultura y el intelecto, de modo que la histeria, estudiada por Freud para iniciar su investigación sobre la conexión entre psique y soma, fue considerada una enfermedad femenina (Gilbert y Gubar, 1998: 67-79). Y a este respecto, Betty Friedan (2009: 328) estudió en 1963 cómo las mujeres que llenaban las clínicas eran la personificación de la mística de la feminidad, porque "la única manera que tiene una mujer, tanto como un hombre, de encontrarse a sí misma [...] es teniendo un trabajo creativo propio" (Friedan, 2009: 411).

No obstante, la literatura también se ha valido del loco, para, como poseedor de cierta sabiduría, constituir el medio a través del cual se critica la sociedad, como puso de manifiesto Foucault (1967: 34), si bien, a partir de la Ilustración, lo irracional ya no tiene cabida en el pensamiento racionalista y ha de ser aislado (Foucault, 1967: 191 y ss). Sin embargo, a menudo la literatura coloca la locura en una instancia cercana a la muerte, donde ya no existen recursos que puedan devolver la razón a personajes como don Quijote o Emma Bovary, imbuidos de lecturas o trastornados por ellas, como tampoco a Marga, convertida en el texto ya en personaje.

Así, la locura puede inscribirse en una escritura femenina, como también lo es la muerte de amor que, muy presente en la mística, en Marga alcanza un estado radical, donde el amado incluso se diviniza (Jiménez, 2015: 42 y 45), y se expresa, al igual que en Teresa de Ávila ${ }^{13}$, a través de un discurso que Juan Ramón tildó de "misticismo sensual" (Jiménez, 2015: 81) y que, según venimos mostrando, tiende a la unión de contrarios:

${ }^{13}$ Según la sobrina de la artista, Marga dejó pendiente las ilustraciones para una biografía de Santa Teresa, además de otras para el Quijote (Jiménez, 2015: 22). 
Ya no quiero vivir sin ti

... no ... ya no puedo vivir sin ti ...

... tú, como sípuedes vivir sin mí

... debes vivir sin mí ... (Jiménez, 2015: 65).

Y así hasta llegar a la noche final, en la que el sujeto, resolviendo la relación entre el eros y la pulsión de muerte, estudiada por Freud (1992) y muy presente en la cultura occidental (Pujante, 2017), desaparece en la textualidad:

... NOCHE última ... que querría

... tanto a tu lado ... y estoy sola ... ... isola! ......

... no ... estoy contigo ...

Yo así en la vida ... estoy,

... $\tan$ inmensamente lejos de ti ... jay!

aunque esté cerca ...

... Pero en la muerte, ya nada me

separa de ti ... solo la muerte

... ... solo la muerte, sola ... y,

es ya ... vida itanto más cerca así

... ... muerte ... cómo te quiero! (Jiménez, 2015: 74).

En este caso, al superar la frontera entre vida y muerte, soledad/ compañía y lejanía/proximidad, se quiebra la dualidad jerarquizada del patriarcado denunciada por Cixous (1995: 13-14), al mismo tiempo que manifiesta una experiencia de pérdida del sujeto, por lo que el misticismo supone un llamamiento especial a las mujeres, cuyo sujeto ha sido negado por el discurso hegemónico (Irigaray, 2007: 175-184).

Nos hallamos, pues, en el pensamiento de Foucault (1993: 16), ante una hiancia, una abertura, que permanecía escondida, porque "el ser del lenguaje no aparece por sí mismo más que en la desaparición del sujeto", en ese discurso silencioso e inconexo que nuestra cultura ha considerado marginal, en la medida en que rehúye el mandato de la representación, si bien emerge en la literatura de los místicos y los vanguardistas desde 
Mallarmé. Por ello Marga, cuando pretende plasmar en el diario su verdad más íntima e inefable acude a la logofagia y la fragmentación, a pesar de que se disculpa por no haber empleado el lenguaje de modo más ortodoxo:

... Juan Ramón, no te debía dar estos escritos así ... desastrosos $y$ malos ... pero, como no puedo ... no me dejas ... ¡decirte todo lo que te quiero! ... qué importa que esté mal dicho ... importa ... la verdad, que yo he sentido tu amor ... digo ... lo siento ... (Jiménez, 2015: 55).

En cualquier caso, nuestra autora construye un espacio textual que posibilite la comunicación con el ser amado, al que continuamente se apela o cuyas palabras, extraídas de diálogos reales o imaginarios, se recogen ${ }^{14}$. Pero también da entrada a otras voces, característica de la autobiografía de mujeres (Masanet, 1998: 37), como las del padre, ordenándole la tarea (Jiménez, 2015: 63), sin olvidar las alusiones a otros miembros de su familia, sobre todo a su hermana, y a Zenobia (Jiménez, 2015: 57), con la que ha establecido una relación que hoy llamaríamos de sororidad: "PORQUE hay Zenobia ... y tú la quieres ... además, es azul y flor y soy su amiga" (Jiménez, 2015: 49). En suma, se advierte una intimidad que pugna por exteriorizarse y que, pese al pacto entre ese yo y el sujeto, con la entrega del diario al poeta, pasa al ámbito privado y después, con la publicación, al público (Castilla del Pino, 1996: 22).

Así, lo íntimo, que designa un espacio reservado e inaccesible, se abre al otro, con el que se pretende la unión más íntima. Es lo que J. Tisseron (2001: 52) ha denominado extimidad y que vuelve inestable la frontera entre dentro/fuera, interior/exterior.

Si el discurso amoroso se dirige a alguien del que no se espera respuesta y, emparentado con la locura (Foessel, 2010: 67-68), se caracteriza por su resistencia al terreno social de los intercambios (Foessel, 2010: 7071 ), esta se agudiza cuando, como en el caso que nos ocupa, deviene en un misticismo extremo en el que se debe morir - “... Y para morirse cuando aún se es joven ... pues ... hay que matarse" (Jiménez, 2015: 65)— para alcanzar la verdadera vida y el estado gozoso, como oposición al principio del placer, que ha de ser superado mediante la vulneración de las normas

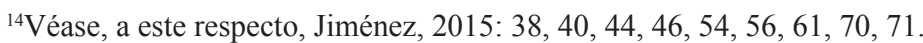


(Lacan, 1988: 214). Así, la consecución del goce, de la jouissance, comporta dolor, pero libera al sujeto de los anclajes psicosociales (Lacan, 1988: 243). Este, entonces, se disuelve en una escritura descentrada y abierta donde enmudece para hablar y tender puentes con la alteridad, que ha de completar el sentido de ese discurso jadeante y diseminado en el que la diarista ha reflejado su yo más íntimo.

\section{REFERENCIAS BIBLIOGRÁFICAS}

ANGENOT, M. (1989). "Le discours social: problématique d'ensemble". En Un état du discours social, M. Angenot, 13-50. Longueuil, Québec: Le Préambule.

BALAGUER PASCUAL, E. et alii (cords.) (2001). Literatura autobiogràfica: història, memòria i contribucció del subjet. Alicante: Denes.

BALLÓ, T. (2018). Las sinsombrero. Sin ellas, la Historia no está completa, I. Barcelona: Espasa.

BEAUVOIR, S. de (1999a). El segundo sexo. Vol. I. Los hechos y los mitos. Madrid: Cátedra.

(1999b). El segundo sexo. Vol. II. La experiencia vivida. Madrid: Cátedra.

BENNINGTON, G. y DERRIDA, J. (1994). Jacques Derrida. Madrid: Cátedra.

BOU, E. (1996). "El diario: periferia y literatura". Revista de Occidente 182-183, 121-135.

BRAIDOTTI, R. (1994). Sujetos nómades. Buenos Aires: Paidós.

BRAUD, M. (2006). La forme des jours. Pour une poétique du journal personnel. Paris: Editions du Seuil.

BRUSS, E. (1991). "Actos literarios”. Suplementos Anthropos 29, 62-79.

BUTLER, J. (2001). El género en disputa. El feminismo y la subversión de la identidad. México: Paidós.

CABALlÉ, A. (1995). Narcisos de tinta. Ensayos sobre literatura autobiográfica en lengua castellana (siglos XIX y XX). Madrid: Megazul.

CAMPILlO MESEGUER, A. (2001). La invención del sujeto. Madrid: Biblioteca Nueva.

CAPDEVILA-ARGÜELLES, N. (2013). Artistas y precursoras, un siglo 
de autoras Roësset. Madrid: Horas y horas.

(2017). Autoras inciertas. Madrid: Sílex.

CASTILLA DEL PINO, C. (1989). Temas. Hombre, cultura, sociedad. Barcelona: Península.

(1996). "Teoría de la intimidad". Revista de Occidente 182-183, 15-30.

(1998) El delirio, un error necesario (Premio Internacional de Ensayo Jovellanos $n .^{\circ} 14$. Oviedo: Nobel.

(2001). "El sujeto como sistema". En Identidades Culturales, M. Á. Hermosilla y A. Pulgarín (eds.), 383-407. Córdoba: Servicio de Publicaciones de la Universidad de Córdoba.

CATELLI, N. (1991). El espacio autobiográfico. Barcelona: Lumen.

(1996). "El diario íntimo: una posición femenina". Revista de Occidente 182-183, 87-98.

CIXOUS, H. (1995). La risa de la medusa. Ensayos sobre la escritura. Barcelona: Anthropos.

COLAIZZI, G. (1990). "Feminismo y Teoría del discurso. Razones para un debate". En Feminismo y Teoría del discurso, G. Colaizzi (ed.), 13-25. Madrid: Cátedra.

CORRADO, C. (2000). Le journal intime en Espagne. Aix-en-Provence: Publications de l'Université de Provence.

DE MAN, P. (1991). "La autobiografía como desfiguración". Suplementos Anthropos 29, 113-118.

DERRIDA, J. (1997). La diseminación. Madrid: Fundamentos.

DÍAZ, B. y SIESS, J. (eds.) (2006). L'Épistolaire au feminine. Correspondances de femmes (XVIII-XX siècle). Caen: Presses Universitaires de Caen.

DIDIER, B. (1996). "El diario, ¿forma abierta?". Revista de Occidente 182-183, 39-46.

EAGLETON, M. (ed.) (1996). Feminist literary theory. A Reader. Oxford: Blackwell.

FERNÁNDEZ, C. y HERMOSILLA, M. a . Á. (eds.) (2004). Autobiografía en España: un balance. Madrid: Visor Libros.

FERNÁNDEZ PRIETO, C. (1994). "La verdad de la autobiografía". Revista de Occidente 154, 116-130.

(2015). "Diario e intimidad". Revista de Occidente 406, 49-70.

FOESSEL, M. (2010). La privación de lo íntimo. Las representaciones 
políticas de los sentimientos. Barcelona: Península.

FOUCAULT, M. (1967). Historia de la locura en la época clásica. México: Fondo de Cultura Económica.

(1979). Microfisica del poder. Madrid: La Piqueta.

(1993). El pensamiento del afuera. Valencia: Pre-Textos.

(1994). Hermenéutica del sujeto. Madrid: La Piqueta.

FREIXAS, L. (1996). “Auge del diario ¿íntimo? en España”. Revista de Occidente 182-183, 5-14.

(2004). "Mujeres, literatura, autobiografía: la singularidad española, o consideraciones sobre un eclipse". En Autobiografia en España: un balance, C. Fernández y M. Á. Hermosilla (eds.), 113-118. Madrid: Visor Libros.

(2015). El silencio de las madres y otras reflexiones sobre las mujeres en la cultura. Barcelona: Aresta Mujeres.

FREUD, S. (1992). "Más allá del placer". En Obras Completas, vol. 18 (1920-1922), 1-62. Buenos Aires: Amorrortu.

FRIEDAN, B. (2009). La mística de la feminidad. Madrid: Cátedra.

GILBERT, S. M. y GUBAR, S. (1998). La loca del desván. La escritora y la imaginación literaria del siglo XIX. Madrid: Cátedra.

GIRARD, A. (1986). Le journal intime. Paris: PUF.

GUERRERO RUIZ, J. (1999). Juan Ramón de viva voz, I (1913-1931). Valencia: Pre-Textos.

HERMOSILlA ÁlVAREZ, M. Á. (2017). "Modulaciones de la jouissance en las poetas de hoy". En Genre et jouissance, C. Flepp et N. Mékouar (eds.), 267-292. Paris: L'Harmattan.

HERNANDO, A. (2012). La fantasía de la individualidad. Sobre la construcción sociohistórica del sujeto moderno. Madrid: Katz.

IRIGARAY, L. (2007). Espéculo de la otra mujer. Madrid: Akal.

JIMÉNEZ, J. R. (ed.) (2015). Marga. Sevilla: Fundación José Manuel Lara.

LACAN, J. (1988). El Seminario. Libro 7. La ética del psicoanálisis, 1959-1960. Buenos Aires: Paidós.

LÁZARO CARRETER, F. y CORREA CALDERÓN, E. (1971). Literatura Española Contemporánea. Salamanca: Anaya.

LEJEUNE, Ph. (1994). El pacto autobiográfico y otros estudios. Madrid: Megazul-Endymión.

LOUREIRO, A. G. (coord.) (1991a) [Monográfico]. "La autobiografía en 
la España contemporánea. Teoría y análisis textual". Anthropos $125,1-78$.

(coord.) (1991b) [Monografías temáticas]. "La autobiografía y sus problemas teóricos. Estudios e investigación documental". Suplementos Anthropos 29, 1-184.

(coord.) (1994). El gran desafio: feminismos, autobiografia y postmodernidad. Madrid: Megazul-Endymión.

LUQUE AMO, Á. (2016). "El diario personal en la literatura: teoría del diario literario". Castilla. Estudios de Literatura 7, 273-306.

(2018). "La construcción del espacio íntimo en el diario literario". Signa. Revista de la Asociación Española de Semiótica 27, 745767.

MARTÍN CLAVIJO, M. et alii (eds.) (2015). Locas. Escritoras y personajes femeninos cuestionando las normas. Sevilla: Arcibel.

MASANET, L. (1998). La autobiografía femenina española contemporánea. Madrid: Fundamentos.

MOI, T. (1995). Teoría literaria feminista. Madrid: Cátedra.

PLANTÉ, C. (ed.) (1998). L'épistolaire, un genre feminine? Paris: Honoré Champion.

POZUELO YVANCOS, J. M. (1993). Poética de la ficción. Madrid: Síntesis.

(2006). De la Autobiografía: teoría y estilos. Barcelona: Crítica.

PUJANTE, D. (2017). Eros y tánatos en la cultura occidental. Un estudio de tematología comparatista. Barcelona: Calambur.

ROMERA CASTILlO, J. (2006). De primera mano. Sobre escritura autobiográfica en España (siglo XX). Madrid: Visor Libros.

ROMERA CASTILLO, J. et alii (eds.) (1993). Escritura autobiográfica. Madrid: Visor Libros.

ROMERA CASTILLO, J. y GUTIÉRREZ CARBAJO, F. (eds.) (1998). Biografias literarias (1975-1997). Madrid: Visor Libros. (2000). Poesía histórica y (auto)biográfica (1975-1999). Madrid: Visor Libros.

ROMERA PINTOR, A. M. (ed.) (2018). [Sección monográfica]. "Escritura autobiográfica femenina en lengua francesa de los siglos XIX al XXI". Signa. Revista de la Asociación Española de Semiótica 28, 15-144 (también en

http://revistas.uned.es/index.php/signa/issue/view/1161 
[01/04/2019]).

SISO MONTER, M. y PLA PÉREZ, S. (2016). "Marga Gil Roësset, la fuerza de la artista innata". En Mujeres de letras: pioneras en el arte, el ensayismo y la educación, M. G. Ríos Guardiola et alii (eds.), 1079-1087. Murcia: Consejería de Educación y Universidades. Secretaría General. Servicio de Publicaciones y Estadística.

SMITH, S. (1991). "Hacia una poética de la autobiografía de mujeres". Suplementos Anthropos 29, 93-105.

TISSERON, S. (2001). L'intimité surexposeé. Paris: Ramsay.

TORRAS, M. (2001). Tomando cartas en el asunto. Las amistades peligrosas de las mujeres con el género epistolar. Zaragoza: PUZ.

TORTOSA, V. (2001). Escrituras ensimismadas: la autobiografía literaria en la democracia española. Alicante: Servicio de Publicaciones de la Universidad de Alicante.

VALIS, N. M. (1991). "La autobiografía como insulto". Anthropos 125, 36-40.

VILLANUEVA, D. (1991). El polen de ideas. Barcelona: PPU.

VIOLI, P. (1991). El infinito singular. Madrid: Cátedra.

ZAMBRANO CARBALLO, P. et alii (2006). Estudios sobre literatura y suicidio. Sevilla: Alfar.

Recibido el 5 de abril de 2019.

Aceptado el 3 de junio de 2019. 